\title{
Hydropower Deserves More Attention!
}

DOI: $10.1134 / \mathrm{S} 0040601520070101$

By the decision of the Editorial Board, certain changes have been introduced into the content and title of the "Energy Conservation, New and Renewable Energy Sources" topical rubric.

These changes primarily concern hydropower. This kind of generation was also addressed on the journal pages in previous years. Matters concerned with the development and operation of small-scale hydropower facilities (with unit capacities up to $10 \mathrm{MW}$ ) were covered in the rubric about renewable energy sources. The role of hydropower for the worldwide energy balance and energy balances of individual countries was touched upon in the "General Subjects" rubric. However, the term "hydropower" did not appear in any of the traditional rubrics of the journal. In the Editorial Board's opinion, such limitations are unfair with respect to the kind of generation that accounts for $16 \%$ of the world's electricity production.

Another change is connected with excluding the term "energy conservation" from the rubric title. Energy conservation was lumped with renewable energy sources (RES) in those far-gone days when no one believed that RESs would become a serious player on the global scale. They were regarded as one of the possible ways for decreasing the consumption of primary energy resources, thus making it possible to save a certain amount of energy. However, for the past 30 years, the state of things in this field has become entirely different: RESs have positively shifted away from the secondary role of an assistant in solving the energy conservation problem and lay claim to a leading role in the modern power industry. In addition, the notion "energy conservation" is very broad, and its traces can easily be found in the articles that are published in the majority of the journal rubrics: turbines, boilers, district heating cogeneration, etc. In view of these reasons, it has been decided to exclude the words "energy conservation" from the rubric title. This does not mean that the Editorial Board is becoming less interested in the eternal problem of achieving efficient generation, transportation, and consumption of energy resources. Materials on this problem will be included in the relevant rubrics as appropriate.

Thus, the rubric title is now formulated as "Renewable Energy Sources and Hydropower." In comparison with the scope that existed hitherto, its content is now broadened by including the following matters of large-capacity hydropower in consideration:

(1) hydroelectric power plants: problems of operation and environmental aspects;

(2) new technical solutions for the designs of hydraulic power units and control systems;

(3) reliability, diagnostics, and power equipment service life;

(4) cavitation and erosion processes in hydraulic machines; and

(5) combined energy sources on the basis of hydraulic power.

The Editorial Board invites the organizations engaged in these problems to submit the results of their investigations for publishing them in the updated rubric of the journal and hopes for fruitful cooperation.

Best regards, A. Klimenko, Editor-in-Chief 